\title{
Evaluating the Efficiency of Industrialization Process in Prefabricated Residential Buildings Using a Fuzzy Multicriteria Decision-Making Method
}

\author{
Huakang Liang, ${ }^{1}$ Shoujian Zhang, ${ }^{2}$ and Yikun $\mathrm{Su}^{3}$ \\ ${ }^{1}$ School of Management, Department of Construction Management, Harbin Institute of Technology, 92 Xidazhi Avenue, Harbin, China \\ ${ }^{2}$ Research Institute of Construction Management, School of Civil Engineering, Harbin Institute of Technology, \\ 92 Xidazhi Avenue, Harbin, China \\ ${ }^{3}$ School of Civil Engineering, Northeast Forestry University, 26 Hexing Road, Harbin, China
}

Correspondence should be addressed to Huakang Liang; hkliang2014@163.com

Received 17 May 2017; Revised 27 July 2017; Accepted 20 August 2017; Published 26 September 2017

Academic Editor: Juan C. Leyva

Copyright $\odot 2017$ Huakang Liang et al. This is an open access article distributed under the Creative Commons Attribution License, which permits unrestricted use, distribution, and reproduction in any medium, provided the original work is properly cited.

To alleviate the housing pressure and achieve a sustainable society, prefabricated residential building (PRB) has witnessed rapid growth in recent years. The usage of prefabricated components in the building represents a significant indicator that is traditionally used to differentiate the PRB from the traditional building. However, it cannot provide details on the efficiency of the industrialization process in the PRB. The main goal of this paper is to develop a composite index to measure the multidimensional concept of industrialization efficiency. Fuzzy Analytic Hierarchy Process (fuzzy AHP) and fuzzy Technique for Order Preference by Similarity to Ideal Solution (fuzzy TOPSIS) are applied to combine the hierarchical structure of indicators into one overall index. Finally, the industrialization efficiency assessment of three PRBs is chosen as a case to illustrate the effectiveness of the method. It can effectively quantify experts' linguistic expressions on the performance of the PRB in different established indicators. This research can provide a decision support tool to assess and continuously promote the improvement of industrialization production in the housing industry.

\section{Introduction}

Prefabrication has been widely used and considered as a potential approach for performance improvements in the housing industry $[1,2]$. Distinct from conventional cast-in situ construction, prefabrication involves a set of construction technologies and processes, through which building components are manufactured in a controlled environment, transported, and assembled on the job-site in order to minimize site works [3,4]. A variety of interchangeable terms are associated with housing that uses the prefabrication technology, such as off-site construction [5], modular housing [6], industrialized building $[3,7]$, modern methods of construction [8], and prefabrication housing [9]. In this study, "prefabricated residential building (PRB)" is used to represent residential buildings that use prefabrication technologies [10]. By contrast, "conventional residential building" refers to the buildings involving cast-in situ technologies [11].
In contrast with traditional buildings, the production of PRB involves many potential benefits, such as enhanced productivity and quality, shortened construction schedule, improved health and safety conditions, and sustainability in terms of environmental, energy, and ecological aspects $[12,13]$. However, the uptake of PRB has been found to be sluggish, especially in some developing countries, such as China, India, and Malaysia [4, 10, 14]. A major reason is that contractors lack experience in using prefabrication and they do not know how to adopt the PRB to their projects effectively [15]. Current industrialized activities in many PRB projects are far from ideal [16]. The production processes suffer from deficiencies in various aspects, such as low level of mechanization, automation, and information technologies. Therefore, it is imperative to develop an integrated decision tool for contractors to assess the efficiency of their PRB practices, through which they can select the most effective production strategies. 
In the following section, the literature concerning PRBrelated practices, definitions, and assessment was reviewed. Then, the methodologies based on both fuzzy Analytic Hierarchy Process (fuzzy AHP) and fuzzy Technique for Order Preference by Similarity to Ideal Solution (fuzzy TOPSIS) were proposed and demonstrated using three PRBs located in the northeast China. The final section offered the conclusions and limitations.

\section{Literature Review}

2.1. PRB-Related Practices and Definitions. PRB has been adopted in housing projects for centuries [17]. Prefabrication has contributed significantly to the efficiency improvement and environmental conservation in the housing industry [10]. Prefabricated and standardized technologies were widely used in reconstruction projects in Asian and European countries during 1950s and the 1960s after World War II [18]. France, for example, was one of the world's earliest countries to implement mass production of housing using prefabrication, whereas Japan was the first country in Asian area in 1965 [19]. In the early 1970s, the American government also introduced several prefabricated building systems, which covered the aspects of prefabrication, standardization, production, and quality control [20]. Hong Kong and Singapore began to adopt prefabrication approaches in housing projects in the 1980s [4, 21]. According to the developing processes of $\mathrm{PRB}$ in different countries, the production characteristics of PRB have shifted from the mass-production approach to the latter mass-customized approach, which had improved the customer orientation and integration of production processes [19].

Various frameworks were used in previous literature to categorize the PRB based on their off-site work. Tam et al. identified three categories of PRB in Hong Kong: semiprefabricated nonstructural components, such as windows and partition walls; comprehensive prefabricated units, such as columns and beams; and modular buildings which are manufactured wholly off-site [22]. Goodier and Gibb classified the PRB into four levels in the UK, including component manufacture and subassembly, nonvolumetric preassembly, volumetric preassembly, and modular buildings [23]. Similarly, In Australia, Blismas and Wakefield defined the off-site system from three categories: nonvolumetric preassembly, volumetric preassembly, and modular building [24].

Industrialization is an essential part of wide modernization process through development of innovative technologies and manufacturing methods [25]. With regard to house building, industrialization of construction primarily refers to the rationalization of construction process through prefabrication in order to achieve the cost efficiency and improved productivity and quality [26]. Six major characteristics of industrialized house building existed in current relevant definitions, including industrialization in transportation, production, and assembly, mass production, on-site fabrication, standardization and structured planning, and process integration [27]. In addition, improved production performance can be achieved through prefabrication, including economic, social, and environmental aspects [28, 29]. Thus, compared with conventional buildings, PRB is the building that can bring significantly rationalized production process and improved production performance.

2.2. PRB Assessment Research. Recently, building assessment is widely used to offer a standard approach to assessing new or existing buildings. Leadership in Energy and Environmental Design (LEED) developed by the American Green Building Council is a voluntary national standard in the USA to promote green buildings [30]. Building Research Establishment Environmental Assessment Method (BREERAM) in the UK is developed to rank the environmental performance of buildings [30]. Intelligent Building Index System is developed by the Asian Institute of Intelligent Building to assess the performance of intelligent building [31]. Meanwhile, the industrialized buildings are also assessed according to the efficiency of their production process. In China, as an illustration, Standard for Assessment of Industrialized Building (SAIB) has been issued in May 2016, which included 99 specific items categorized in four-dimension design, manufacture, management, and benefits for assessing the efficiency of PRB implementation [32].

Various criteria or indicators were used to assess the $\mathrm{PRB}$ in terms of the efficiency of their production process in previous studies, such as prefabricated ratio or degree of off-site production [23, 33]; degree of product standardization [34]; extent of mechanization and automation [26]; integration of supply chain management in production [35]. Therefore, the assessment of industrialization efficiency of $\mathrm{PRB}$ is a multicriteria decision-making (MCDM) problem, which involves multiple, usually conflicting, decision criteria [31]. De Barba et al. applied a MCDM technique to compare the industrialized and traditional building systems from three aspects of sustainability: environmental, economic, and social aspects [12]. Alinaitwe et al. recommended twelve indicators of measurement to determine the efficiency of industrialization process in the PRB [26]. Lessing et al. established a categorization model for the efficiency of PRB production based on eight indicators [35].

As two most known MCDM techniques, AHP and TOPSIS have been widely used in building performance evaluation, such as intelligent building [31], building energy conservation [36], building day-lighting and tradition continuity [37], and green building [38]. Based on the theory of fuzzy sets proposed by Zadeh [39], fuzzy MCDM is developed to deal with qualitative, imprecise, and ill-structured information during the decision process [40]. However, the fuzzy AHP and TOPSIS have not been applied to assess the efficiency of PRB. The assessment of PRB, as a MCDM problem, is related to vague criteria and subjective opinions of decision-makers. To overcome these limitations, this study proposed a fuzzy AHP-TOPSIS approach to assessing the industrialization efficiency of PRB.

\section{Methodologies}

This study proposed a fuzzy AHP-TOPSIS approach to assessing the PRB in terms of their industrialization efficiency for promoting the industrialization practices in the housing 


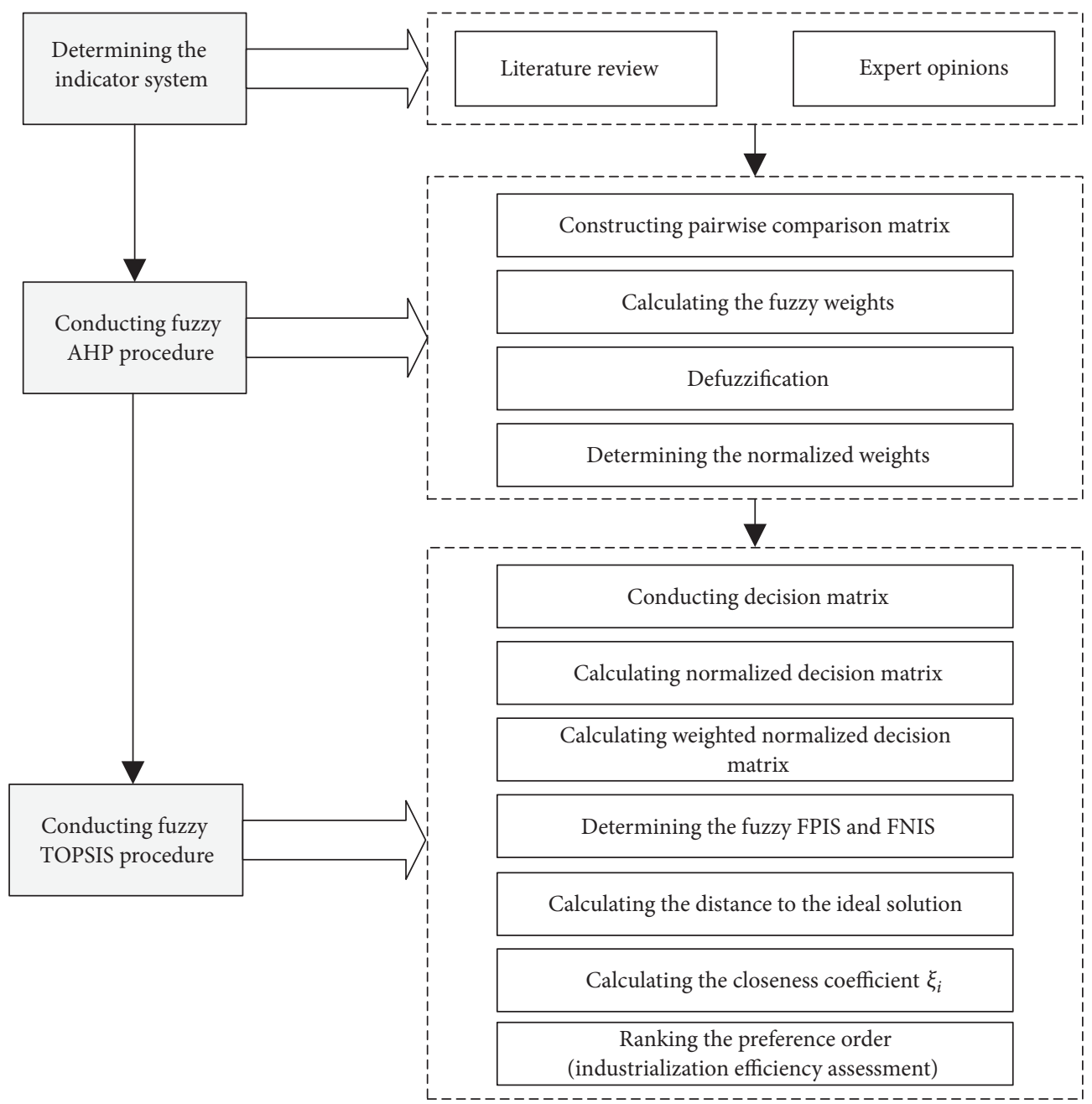

FIGURE 1: Main process of assessing the efficiency of industrialization process in the PRB.

industry. The research process consisted of three stages: (1) critical measurement indicators were identified. At this stage, influential criteria and measurement indicators were determined through PRB-related literature and expert opinions. (2) The fuzzy AHP method was utilized to determine the importance weights of the criteria and indicators. (3) The fuzzy TOPSIS method was employed to condense multilayer indicators into a composite index to present the efficiency of PRB's industrialization practices. The specific research procedure was shown as Figure 1.

3.1. Determining the Assessment Indicator System. As mentioned earlier, the major characteristics of PRB involve two dimensions: industrialized production process and improved production performance. Therefore, industrialization efficiency of PRB is assessed from the two aspects. A comprehensive review of previous literature related to the PRB was conducted to identify the factors that have significant impacts on the industrialization efficiency of PRB $[12,13$, $23,26,28,29,31-33,35,41-43]$. Finally, five criteria regarding the industrialized production process were identified, including standardized design, off-site manufacture, on-site construction, component transportation, and collaboration management. One criterion, sustainability, was identified to interpret improved production performance. Then, these six criteria were further measured by relevant subcriteria (indicators), and a preliminary draft of indicator system was determined subsequently. Six domain experts, including four scholar researchers and two practitioners, were invited to provide the qualitative validation of the measurements. Their average working experience was fifteen years in the industrialized building field. Several modifications were performed through simplifying, rephrasing, and eliminating relevant items three times. Finally, the initial indicator system was obtained, including six criteria and twenty three subcriteria (indicators), as shown in Table 1.

3.2. Fuzzy AHP. AHP is developed to address complex MCDM problems, involving multiple quantitative and qualitative criteria [44]. Considering the vagueness of experts' judgments, several fuzzy AHP methods which integrate fuzzy set theory and basic AHP have been proposed in recent years [31]. In fuzzy AHP, the pairwise comparisons of indicators are conducted using linguistic variables, which are represented 


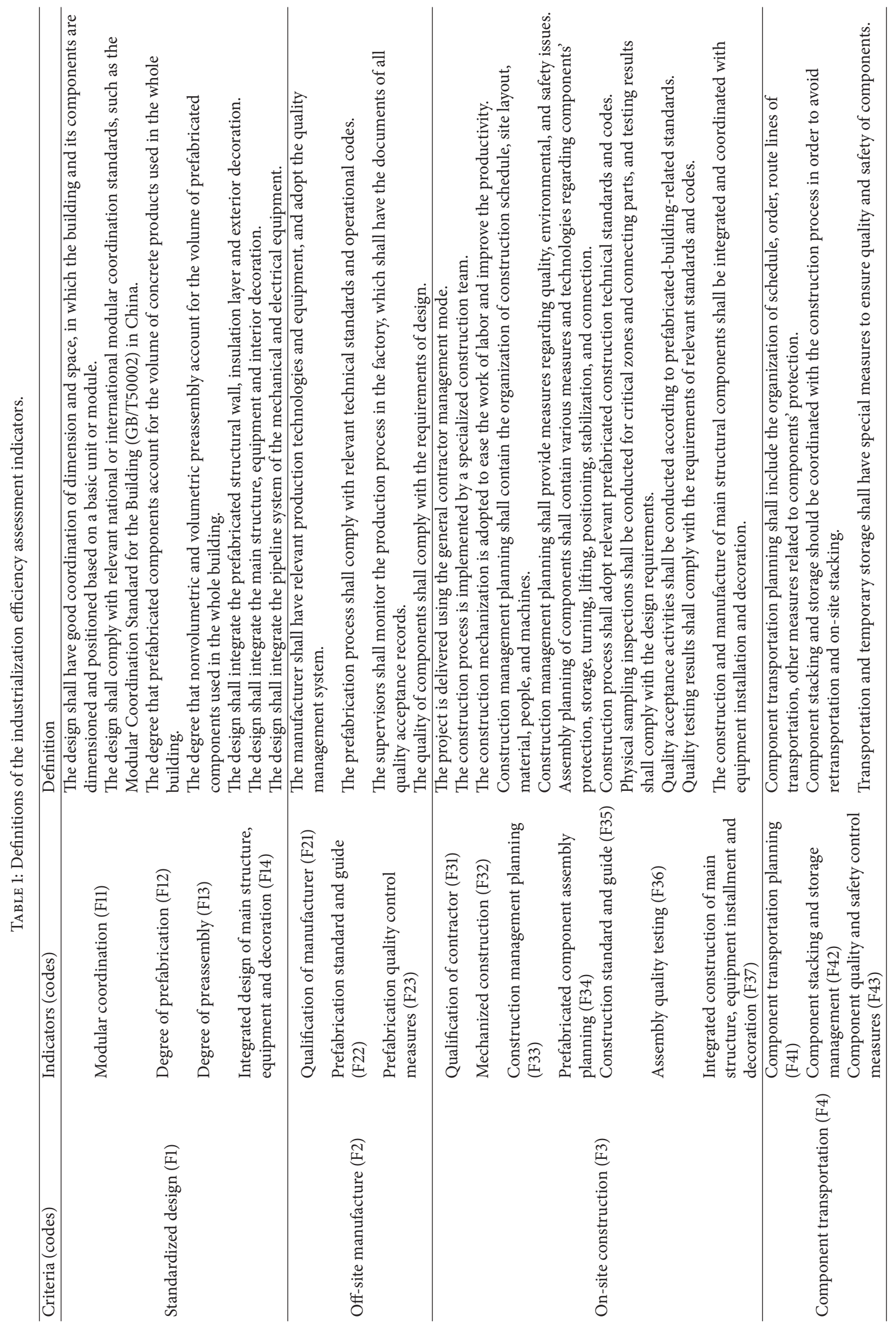




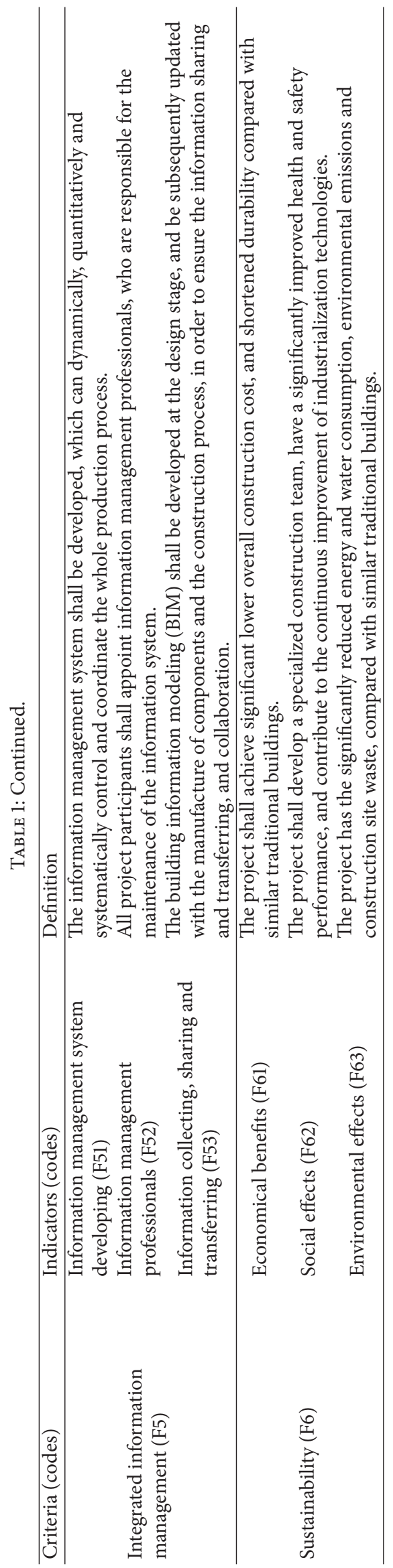


TABLE 2: Linguistic scale for the pairwise matrix.

\begin{tabular}{lc}
\hline Linguistic variables & Triangular fuzzy numbers \\
\hline Equally important & $(1,1,3)$ \\
Weakly important & $(1,3,5)$ \\
Essentially important & $(3,5,7)$ \\
Very strongly important & $(5,7,9)$ \\
Absolutely important & $(7,9,9)$ \\
\hline
\end{tabular}

by triangular numbers [45]. In this study, Buckley' fuzzy AHP method was used [46]. The steps of fuzzy AHP are illustrated as follows $[31,47]$.

Step 1 (determining the pairwise comparison matrices). Experts compare the criteria or subcriteria using the linguistic terms that are shown in Table 2 [47]. The pairwise comparison matrix can be expressed in matrix form as in

$$
\widetilde{C}_{k}=\left[\begin{array}{cccc}
1 & \widetilde{c}_{12} & \cdots & \widetilde{c}_{1 n} \\
\widetilde{c}_{21} & 1 & \cdots & \widetilde{c}_{2 n} \\
\vdots & \vdots & \cdots & \vdots \\
\widetilde{c}_{n 1} & \widetilde{c}_{n 2} & \cdots & 1
\end{array}\right],
$$

where $\widetilde{c}_{i j}$ is a linguistic term representing the importance of a criterion over the other one. $\widetilde{C}_{k}$ is the pairwise comparison matrix obtained from the expert $e_{k}, k=1,2,3, \ldots, K$. The expert opinions are aggregated using the geometric mean method (GMM), which is more consistent with the meanings of judgments in AHP [48].

Step 2 (calculating the fuzzy weights). The fuzzy weight matrix is calculated as

$$
\begin{aligned}
\widetilde{r}_{i} & =\left(\widetilde{c}_{i 1} \otimes \widetilde{c}_{i 2} \otimes \cdots \otimes \widetilde{c}_{i n}\right)^{1 / n}, \\
\widetilde{w}_{i} & =\widetilde{r}_{i} \otimes\left(\widetilde{r}_{1}+\widetilde{r}_{2}+\cdots+\widetilde{r}_{n}\right)^{-1},
\end{aligned}
$$

where $\tilde{r}$ represents the geometric mean of fuzzy comparison values of each criterion. $\widetilde{w}_{i}=\left(L_{i}, M_{i}, U_{i}\right)$ is the fuzzy weight of the criterion $i$.

Step 3 (defuzzification). The fuzzy weights are converted into a crisp value using the defuzzification process. The center of gravity defuzzification [49] was used in this study, which is calculated using

$$
\bar{w}_{i}=\frac{L_{i}+M_{i}+U_{i}}{3} .
$$

Step 4 (determining the normalized weights). The weight value $\bar{w}_{i}$ should be normalized using

$$
w_{i}=\frac{\bar{w}_{i}}{\sum_{i=1}^{n} \bar{w}_{i}} .
$$

TABLE 3: Triangular fuzzy number for each linguistic value in the research.

\begin{tabular}{lc}
\hline Linguistic value & Triangular fuzzy number \\
\hline Very poor & $(0,0,1)$ \\
Poor & $(0,1,3)$ \\
Medium poor & $(1,3,5)$ \\
Fair & $(3,5,7)$ \\
Medium good & $(5,7,9)$ \\
Good & $(7,9,10)$ \\
Very good & $(9,10,10)$ \\
\hline
\end{tabular}

3.3. Fuzzy TOPSIS. The TOPSIS method was first developed by Hwang et al. [50], for solving the MCDM problems based on the priority that the chosen alternative should have the shortest distance from the positive ideal solution (PIS) and the farthest distance from the negative ideal solution (NIS) [51]. Considering the MCDM problems often involve vague criteria and subjective opinions of experts, the TOPSIS has been extended in the fuzzy environment, where the ratings of alternatives were described by linguistic assessments quantified with triangular fuzzy numbers [52]. The linguistic variable is a special variable whose value is a linguistic term such as "low, very low, and so forth." The linguistic variable is useful to describe qualitative and vague information [51]. In this research, the fuzzy TOPSIS was used to assess the industrialization efficiency of PRB. Triangular fuzzy numbers were used to quantify the linguistic value, as set forth in Table 3. The steps of fuzzy TOPSIS are described as follows [51].

Step 5 (constructing the fuzzy decision matrix). The fuzzy decision matrix is constructed as shown in (5). $\left[\begin{array}{llll}B_{1} & B_{2} & \cdots & B_{m}\end{array}\right]$ denotes $m$ PRBs; $\left[\begin{array}{llll}C_{1} & C_{2} & \cdots & C_{n}\end{array}\right]$ denotes $n$ indicators involved in the assessment process; $t_{i j}$ is the triangular fuzzy number $\left(t_{i j}^{(L)}, t_{i j}^{(M)}, t_{i j}^{(U)}\right)$ for PRB $B_{i}$ with respect to factor $F_{j}$, which is determined through the linguistic assessment according to Table 3 . The ratings of group judgments are aggregated using (6), where $K$ is the number of experts and $t_{i j}^{K}$ represents the rating by the $K$ th expert.

$$
\begin{aligned}
\widetilde{D} & =\left[\begin{array}{ccccc} 
& C_{1} & C_{2} & \cdots & C_{n} \\
B_{1} & t_{11} & t_{12} & \cdots & t_{1 n} \\
B_{2} & t_{21} & t_{22} & \cdots & t_{2 n} \\
\vdots & \vdots & \vdots & \ddots & \vdots \\
B_{m} & t_{m 1} & t_{m 2} & \cdots & t_{m n}
\end{array}\right], \\
t_{i j} & =\frac{1}{K}\left[t_{i j}^{1} \oplus t_{i j}^{2} \oplus \cdots \oplus t_{i j}^{K}\right] .
\end{aligned}
$$

Step 6 (calculating the normalized fuzzy decision matrix). The normalized fuzzy decision matrix is determined using the linear scale transformation to transform various factor scales into a comparable scale. The transformation processes 
are demonstrated as (7), (8), and (9) [53]. If factor $C_{j}$ is the benefit indicator (namely, the more, the better), its normalized formula is shown as (8), whereas, if factor $C_{j}$ is the cost indicator (namely, the less, the better), its normalization is shown as (9).

$$
\begin{aligned}
S= & {\left[s_{i j}\right]_{m \times n}, } \\
& s_{i j}=\left(s_{i j}^{L}, s_{i j}^{M}, s_{i j}^{U}\right), i=1,2, \ldots, m ; j=1,2, \ldots, n, \\
s_{i j}= & \left(\frac{t_{i j}^{L}}{t_{j}^{U *}}, \frac{t_{i j}^{M}}{t_{j}^{U *}}, \frac{t_{i j}^{U}}{t_{j}^{U *}}\right), \\
s_{i j}= & \left(\frac{t_{j}^{L-}}{t_{i j}^{L}}, \frac{t_{j}^{L-}}{t_{i j}^{M}}, \frac{t_{j}^{L-}}{t_{i j}^{U}}\right), \quad t_{j}^{L-}=\min _{i}^{U *} t_{i j}^{L}, i=\max _{i} t_{i j}^{U}, i=1,2, \ldots, m, \ldots, n .
\end{aligned}
$$

Step 7 (calculating weighted normalized fuzzy decision matrix). According to the weights of factors calculated by the fuzzy AHP as mentioned above, the weighted normalized fuzzy decision matrix is determined as (10), where $\widetilde{s}_{i j}=w_{j} \cdot s_{i j}$.

$$
\begin{aligned}
\widetilde{S}= & {\left[\widetilde{s}_{i j}\right]_{m \times n}, } \\
& \widetilde{s}_{i j}=\left(\widetilde{s}_{i j}^{L}, \widetilde{s}_{i j}^{M}, \widetilde{s}_{i j}^{U}\right), i=1,2, \ldots, m ; j=1,2, \ldots, n .
\end{aligned}
$$

Step 8 (determining the fuzzy positive idea solution (FPIS) and fuzzy negative idea solution (FNIS)). According to the weighted normalized matrix, FPIS and FNIS are defined as (11) and (12) [54]. In other words, each value of an element in FNIS is equal to $(0,0,0)$, and the value of element $\widetilde{s}_{j}^{+}$in FPIS is equal to $\left(w_{j}, w_{j}, w_{j}\right)$, where $w_{j}$ is the weight of criterion $C_{j}$.

$$
\begin{aligned}
& \text { FPIS: } A^{+}=\left(\widetilde{s}_{1}^{+}, \widetilde{s}_{2}^{+}, \ldots, \widetilde{s}_{n}^{+}\right), \\
& \text {FNIS: } A^{-}=\left(\widetilde{s}_{1}, \widetilde{s}_{2}, \ldots, \widetilde{s}_{n}^{-}\right),
\end{aligned}
$$

where $\widetilde{s}_{j}^{+}=\left(\widetilde{s}_{j}^{+(L)}, \widetilde{s}_{j}^{+(M)}, \widetilde{s}_{j}^{+(U)}\right) ; \widetilde{s}_{j}=\left(\widetilde{s}_{j}^{(L)}, \widetilde{s}_{j}^{-(M)}, \widetilde{s}_{j}^{-(U)}\right)$

$$
\begin{aligned}
& \widetilde{s}_{j}^{+}=w_{j} \otimes(1,1,1), \\
& \widetilde{s_{j}}=(0,0,0) .
\end{aligned}
$$

Step 9 (calculating the distance of the alternative sequence $\widetilde{s}_{i}=\left[\widetilde{s}_{i 1}, \widetilde{s}_{i 2}, \ldots, \widetilde{s}_{i n}\right]$ to FPIS and FNIS). The calculation process is shown as (13) and (14).

$$
\begin{aligned}
& d_{i}^{+}=\sum_{j=1}^{n} d\left(\widetilde{s}_{j}^{+}, \widetilde{s}_{i j}\right), \quad i=1,2, \ldots, m, \\
& d_{i}^{-}=\sum_{j=1}^{n} d\left(\widetilde{s}_{j}^{-}, \widetilde{s}_{i j}\right), \quad i=1,2, \ldots, m,
\end{aligned}
$$

where

$$
\begin{aligned}
& d\left(\widetilde{s}_{j}^{+}, \widetilde{s}_{i j}\right) \\
& =\sqrt{\frac{1}{3}\left[\left(\widetilde{s}_{i j}^{(L)}-\widetilde{s}_{j}^{+(L)}\right)^{2}+\left(\widetilde{s}_{i j}^{(M)}-\widetilde{s}_{j}^{+(M)}\right)^{2}+\left(\widetilde{s}_{i j}^{(U)}-\widetilde{s}_{j}^{+(U)}\right)^{2}\right]}, \\
& d\left(\widetilde{s}_{j}, \widetilde{s}_{i j}\right) \\
& =\sqrt{\frac{1}{3}\left[\left(\widetilde{s}_{i j}^{(L)}-\widetilde{s}_{j}^{-(L)}\right)^{2}+\left(\widetilde{s}_{i j}^{(M)}-\widetilde{s}_{j}^{(M)}\right)^{2}+\left(\widetilde{s}_{i j}^{(U)}-\widetilde{s}_{j}^{(U)}\right)^{2}\right]} .
\end{aligned}
$$

Step 10 (calculating the closeness coefficient $\xi_{i}$ ). The closeness coefficient $\xi_{i}$ for each alternative sequence with respect to FPIS is calculated as

$$
\xi_{i}=\frac{d_{i}^{-}}{d_{i}^{-}+d_{i}^{+}}, \quad i=1,2, \ldots, m .
$$

Step 11 (determining the industrialization efficiency and prioritizing alternatives). The closeness coefficient $\xi_{i}$ is in the interval of $(0,1)$. Generally, the higher the closeness coefficient $\xi_{i}$ of alternative $\widetilde{s}_{i}$, the closer the alternative to the $\operatorname{FPIS}\left(A^{+}\right)$. Thus, $\xi_{i}$ is regarded as the industrialization efficiency of PRB $B_{i}$ because FPIS represents the optimal status of PRB production process. According to $\xi_{i}$, the ranking order of alternatives can be determined according to the value of industrialization efficiency.

\section{Empirical Study}

With the rapid development of the national economy, increasing labor costs, and growing requirements for sustainable society, the usage of PRB in China has expanded since the middle 2000s [4]. In this study, three PRB buildings located in northeast China, denoted by PRB-A, PRB-B, and PRB-C, were selected to validate the proposed approach. Specifically, PRB-A is a 15-story residential building with a prefabrication ratio of $85 \%$ and construction area of $10280.58 \mathrm{~m}^{2}$; PRB-B is a 12 -story residential building with a prefabrication ratio of $60 \%$ and construction area of $11795.23 \mathrm{~m}^{2}$; PRB-C is a 15 -story residential building with a prefabrication ratio of $55 \%$ and construction area of $14321.56 \mathrm{~m}^{2}$. Note that the prefabrication ratio represents the degree of prefabrication in each PRB. To collect relevant data for industrialization efficiency assessment, documents and records regarding the production processes of three PRBs were examined.

In order to determine the importance weights of 23 indicators and the corresponding 6 criteria, a questionnaire survey was conducted. The questionnaire consisted of seven pairwise comparison matrices: six used to determine the relative importance of each indicator in comparison with the other indicator in terms of one criterion and one overall matrix used to determine the relative importance between two criteria in terms of overall goal. Five-level linguistic scales were used to reflect the relative importance value between two indicators or criteria (shown as Table 2). The questionnaire was associated with a presentation letter, which informed the respondents about the research aim and method. Finally, the questionnaire was sent via email to 40 
TABLE 4: Local and global importance weights of 6 criteria and 23 indicators.

\begin{tabular}{|c|c|c|c|c|c|c|}
\hline Criteria & Fuzzy & Weights & Indicators & Fuzzy & Local weights & Global weights \\
\hline \multirow{4}{*}{$\mathrm{F} 1$} & \multirow{4}{*}{$(0.167,0.362,0.812)$} & \multirow{4}{*}{0.36} & F11 & $(0.089,0.162,0.382)$ & 0.19 & 0.0684 \\
\hline & & & $\mathrm{F} 12$ & $(0.350,0.615,1.061)$ & 0.60 & 0.216 \\
\hline & & & $\mathrm{F} 13$ & $(0.023,0.047,0.092)$ & 0.05 & 0.018 \\
\hline & & & F14 & $(0.076,0.176,0.325)$ & 0.17 & 0.0612 \\
\hline \multirow{3}{*}{$\mathrm{F} 2$} & \multirow{3}{*}{$(0.049,0.114,0.263)$} & \multirow{3}{*}{0.11} & F21 & $(0.404,0.730,1.281)$ & 0.72 & 0.0792 \\
\hline & & & $\mathrm{F} 22$ & $(0.088,0.149,0.312)$ & 0.16 & 0.0176 \\
\hline & & & $\mathrm{F} 23$ & $(0.054,0.122,0.240)$ & 0.12 & 0.0132 \\
\hline \multirow{7}{*}{ F3 } & \multirow{7}{*}{$(0.110,0.246,0.590)$} & \multirow{7}{*}{0.25} & F31 & $(0.035,0.116,0.30)$ & 0.11 & 0.0275 \\
\hline & & & F32 & $(0.015,0.042,0.124)$ & 0.05 & 0.0125 \\
\hline & & & F33 & $(0.175,0.437,0.945)$ & 0.39 & 0.0975 \\
\hline & & & F34 & $(0.054,0.112,0.416)$ & 0.14 & 0.035 \\
\hline & & & F35 & $(0.039,0.109,0.357)$ & 0.13 & 0.03125 \\
\hline & & & F36 & $(0.034,0.104,0.306)$ & 0.11 & 0.0275 \\
\hline & & & F37 & $(0.024,0.080,0.224)$ & 0.08 & 0.02 \\
\hline \multirow{3}{*}{$\mathrm{F} 4$} & \multirow{3}{*}{$(0.031,0.083,0.179)$} & \multirow{3}{*}{0.08} & F41 & $(0.407,0.728,1.282)$ & 0.71 & 0.0568 \\
\hline & & & F42 & $(0.086,0.196,0.377)$ & 0.19 & 0.0152 \\
\hline & & & $\mathrm{F} 43$ & $(0.046,0.076,0.196)$ & 0.09 & 0.0072 \\
\hline \multirow{3}{*}{ F5 } & \multirow{3}{*}{$(0.046,0.111,0.273)$} & \multirow{3}{*}{0.12} & F51 & $(0.149,0.287,0.799)$ & 0.34 & 0.0408 \\
\hline & & & F52 & $(0.046,0.085,0.194)$ & 0.09 & 0.0108 \\
\hline & & & F53 & $(0.252,0.628,1.245)$ & 0.58 & 0.0696 \\
\hline \multirow{3}{*}{ F6 } & \multirow{3}{*}{$(0.033,0.083,0.176)$} & \multirow{3}{*}{0.08} & F61 & $(0.269,0.494,1.088)$ & 0.51 & 0.0408 \\
\hline & & & F62 & $(0.052,0.116,0.293)$ & 0.13 & 0.0104 \\
\hline & & & F63 & $(0.131,0.390,0.832)$ & 0.37 & 0.0296 \\
\hline
\end{tabular}

experts with at least 5 years of experience in the industrialized building field, including 20 research scholars, 10 practitioners, and 10 regulators.

Then, regarding the performance of 3 target $\mathrm{PRBs}$, nine experts were further invited to review production-related documents and data records according to the established indicators depicted in Table 1 . The average working experience of 9 experts related to industrialized building was 12 years. The performance of alternatives with respect to each indicator was assessed using a seven-level linguistic scale (shown as Table 3).

4.1. Determining the Weights of Indicators. A total of 21 valid questionnaires were recovered. These 21 respondents were formed of 9 research scholars, 7 practitioners, and 5 regulators, with an overall response rate of $52.5 \%$ and subgroup response rates of $45 \%, 70 \%$, and $50 \%$, respectively. The diversity of the respondents was a guarantee of obtaining reliable assessment results. The geometric means method was employed to aggregate the group judgments. Based on the seven pairwise comparison matrices of main criteria and indicators, priority weights of indicators were calculated based on the fuzzy AHP as mentioned earlier. The local and global weights of each indicator were shown in Table 4 . The weighted ranking of six criteria from high to low are as follows: standardized design (0.36), on-site construction (0.25), integrated information management (0.12), off-site manufacture (0.11), component transportation (0.08), and sustainability (0.08). As for the global weights of indicators under each criterion, degree of prefabrication is the most influential indicator for the industrialization efficiency of the PRB, with a global weight of 0.216 . For the criterion of standardized design, degree of prefabrication is the most important with a local weight of 0.60 ; for off-site manufacture, qualification of manufacturer is top one indicator, with a weight of 0.72 ; for on-site construction, construction management planning is the critical indicator, with a weight of 0.39 ; for component transportation, component transportation planning is the critical indicator (0.71); for integrated information management, information collecting, sharing, and transferring are the critical indicator (0.58); for sustainability, economical benefits are the critical indicator (0.51).

4.2. Determining the Industrialization Efficiency. Linguistic assessments were conducted to assess performance of three PRBs according to established indicators in Table 1 and the seven-level linguistic scale listed in Table 3 . The ratings of nine experts were aggregated using (5) and (6). The industrialization efficiency of PRB-A, PRB-B, and PRB-C was determined using the fuzzy TOPSIS [51]. The FPIS and FNIS were obtained using (11) and (12). The distances of individual indicators from the FPIS and FNIS were calculated 
TABLE 5: The distances of three PRBs from FPIS and FNIS.

\begin{tabular}{|c|c|c|c|c|c|c|c|}
\hline \multirow{2}{*}{$d\left(\widetilde{s}_{j}^{+}, \widetilde{s}_{i j}\right)$} & \multicolumn{3}{|c|}{ PRBs (by FPIS) } & \multirow{2}{*}{$d\left(\widetilde{s_{j}}, \widetilde{s}_{i j}\right)$} & \multicolumn{3}{|c|}{ PRBs (by FNIS) } \\
\hline & PRB-A & PRB-B & PRB-C & & PRB-A & PRB-B & PRB-C \\
\hline F11 & 0.00904 & 0.01475 & 0.032036 & F11 & 0.061843 & 0.056948 & 0.041758 \\
\hline F12 & 0.025709 & 0.041342 & 0.079471 & F12 & 0.198849 & 0.17855 & 0.138088 \\
\hline $\mathrm{F} 13$ & 0.004678 & 0.006705 & 0.007154 & $\mathrm{~F} 13$ & 0.01364 & 0.011555 & 0.01145 \\
\hline F14 & 0.040649 & 0.030356 & 0.017143 & F14 & 0.021881 & 0.03311 & 0.04463 \\
\hline F 21 & 0.026204 & 0.017508 & 0.014445 & F21 & 0.055031 & 0.066995 & 0.067511 \\
\hline F22 & 0.003152 & 0.009513 & 0.00588 & $\mathrm{~F} 22$ & 0.014712 & 0.00848 & 0.012172 \\
\hline F23 & 0.001643 & 0.005381 & 0.005127 & F23 & 0.011969 & 0.008413 & 0.009058 \\
\hline F31 & 0.001588 & 0.010413 & 0.009768 & F31 & 0.026615 & 0.018584 & 0.019043 \\
\hline F32 & 0.001846 & 0.001781 & 0.003151 & F32 & 0.011052 & 0.011089 & 0.009657 \\
\hline F33 & 0.011928 & 0.037127 & 0.047715 & F33 & 0.089092 & 0.066486 & 0.055683 \\
\hline F34 & 0.003137 & 0.010572 & 0.010276 & F34 & 0.032858 & 0.02567 & 0.026336 \\
\hline F35 & 0.00517 & 0.011683 & 0.012518 & F35 & 0.026406 & 0.020723 & 0.02074 \\
\hline F36 & 0.002647 & 0.005372 & 0.00476 & F36 & 0.025343 & 0.022978 & 0.02328 \\
\hline F37 & 0.004468 & 0.003262 & 0.004481 & F37 & 0.016532 & 0.017435 & 0.016454 \\
\hline F41 & 0.017823 & 0.023098 & 0.016547 & F41 & 0.042193 & 0.037045 & 0.044175 \\
\hline $\mathrm{F} 42$ & 0.00298 & 0.007389 & 0.003499 & F42 & 0.013295 & 0.008815 & 0.012653 \\
\hline $\mathrm{F} 43$ & 0.003204 & 0.004166 & 0.002134 & F43 & 0.00458 & 0.003489 & 0.005552 \\
\hline F51 & 0.007531 & 0.016201 & 0.008207 & F51 & 0.034797 & 0.026992 & 0.03495 \\
\hline F52 & 0.005997 & 0.003189 & 0.004191 & F52 & 0.005084 & 0.008038 & 0.007249 \\
\hline F53 & 0.015764 & 0.040222 & 0.026567 & F53 & 0.057025 & 0.032692 & 0.047835 \\
\hline F61 & 0.004856 & 0.019631 & 0.012288 & F61 & 0.03756 & 0.023014 & 0.030642 \\
\hline F62 & 0.002441 & 0.002864 & 0.004009 & F62 & 0.008876 & 0.008336 & 0.00722 \\
\hline F63 & 0.006832 & 0.01139 & 0.017426 & F63 & 0.023924 & 0.020251 & 0.01367 \\
\hline$d_{i}^{+}$ & 0.209285 & 0.333914 & 0.348796 & $d_{i}^{-}$ & 0.83316 & 0.715687 & 0.699806 \\
\hline
\end{tabular}

FPIS: fuzzy positive ideal solution; FNIS: fuzzy negative ideal solution; $d\left(\widetilde{s}_{j}^{+}, \widetilde{s}_{i j}\right)$ is the distance between factor $j$ in the alternative sequence and the FPIS, and $d\left(\widetilde{s}_{j}, \widetilde{s}_{i j}\right)$ is the distance between factor $j$ in the alternative sequence and the FNIS; $d_{i}^{+}$is the sum of distance for $d\left(\widetilde{s}_{j}^{+}, \widetilde{s}_{i j}\right)$, and $d_{i}^{-}$is the sum of distance for $d\left(\widetilde{s_{j}}, \widetilde{s}_{i j}\right)$.

using (13) and (14). The FPIS and FNIS distances for three alternatives were demonstrated in Table 5. Next, the closeness coefficient was calculated using (15). The closeness coefficient represented the efficiency of each $\mathrm{PRB}$ in the industrialization production, namely, the industrialization efficiency. Thus, the overall ranking of three PRBs in terms of industrialization efficiency was determined: PRB-A, PRB-B, and PRB-C (shown as Table 6). The rankings by six specific criteria were obtained accordingly, which were also presented in Table 6.

The layout of the industrialization efficiency of three PRBs under the overall performance and five different criteria is shown in Figure 2 to give necessary insights into their strengths and weaknesses in terms of industrialization production. The closed area of PRB-A approximately encompasses other two PRBs, indicating its dominant position regarding the efficiency of industrialization production. The rankings show significant deviations under the criteria of off-site manufacture and component transportation from the overall rankings. The production of PRB-C achieves relative higher performance under the two criteria, while PRB-A and PRB-C suffer from some deficiencies. The specific problem areas (indicators) under the two criteria can be identified based on the distance of each indicator to the ideal

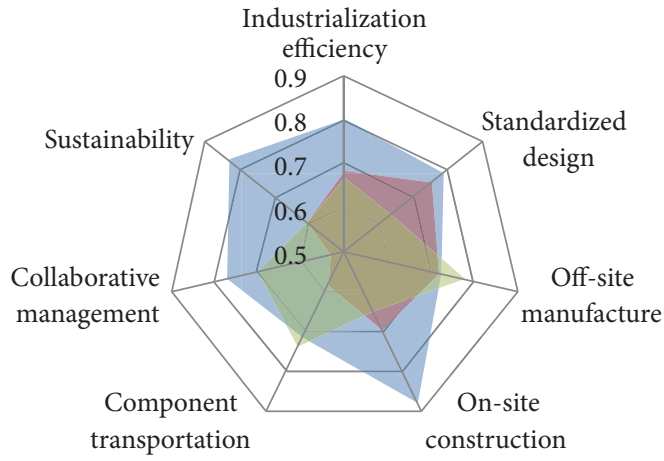

$$
\begin{array}{r}
\text { PRB-A } \\
\text { PRB-B } \\
\text { PRB-C }
\end{array}
$$

FIGURE 2: The distribution of industrialization efficiency of three PRBs.

solution, which is shown in Table 5. PRB-A, as an illustration, has the weaknesses under the component transportation planning (F41) and component quality and safety control measures (F43) compared with PRB-C. Thus, based on the 
TABLE 6: The ranking of PRBs by the industrialization efficiency and individual criteria.

\begin{tabular}{|c|c|c|c|}
\hline PRBs & PRB-A & PRB-B & PRB-C \\
\hline Industrialization efficiency & 0.799236 & 0.681866 & 0.667371 \\
\hline Rank & 1 & 2 & 3 \\
\hline Standardized design & 0.787196 & 0.750471 & 0.634668 \\
\hline Rank & 1 & 2 & 3 \\
\hline Off-site manufacture & 0.724969 & 0.721366 & 0.777107 \\
\hline Rank & 2 & 3 & 1 \\
\hline On-site construction & 0.881001 & 0.695224 & 0.648796 \\
\hline Rank & 1 & 2 & 3 \\
\hline Component transportation & 0.714456 & 0.587474 & 0.737698 \\
\hline Rank & 2 & 3 & 1 \\
\hline Integrated information management & 0.767895 & 0.531846 & 0.697946 \\
\hline Rank & 1 & 3 & 2 \\
\hline Sustainability & 0.832773 & 0.603622 & 0.604442 \\
\hline Rank & 1 & 3 & 2 \\
\hline
\end{tabular}

results, the contractors, as producers of three PRBs, can make positive adjustments to promote the effectiveness of identified problem areas during the future industrialization practices of PRBs.

\section{Conclusion}

PRB has attracted increasing attentions from both researchers and practitioners due to its potentials to enhance productivity and meet the requirements for achieving a sustainable society. However, there is still lack of a reliable assessment tool for assessing the efficiency of the industrialization production. One significant contribution in this study is the proposed PRB assessment model, which allows contractors to track the performance of their PRB practices and identify effective strategies. Based on the extensive literature review and expert opinions, the industrialization efficiency of PRB was depicted using six criteria, including standardized design, off-site manufacture, on-site construction, component transportation, integrated information management, and sustainability. Six criteria, representing both production process and performance, were further interpreted using twentythree indicators. The PRB assessment tool can provide more comprehensive information on the status of industrialization production. The fuzzy AHP and TOPSIS were applied to combine multilayer indicators into one overall industrialization index. In addition, this approach took into account the vagueness of expert's opinions and could effectively handle experts' linguistic expressions.

The study provided a set of criteria and indicators for extracting information on the industrialization efficiency of PRB. Based on the importance weights, this study found that standardized design and on-site construction were two most influential criteria for improving the industrialization performance. The critical indicators under each criterion were further determined, including degree of prefabrication, qualification of manufacturer, construction management planning, component transportation planning, information collecting, sharing, and transferring, and economical benefits. Both contractors and policy makers should pay more attentions to the critical factors for promoting the industrialized building. In addition, the proposed model can be used as decision support systems. The policy makers can assess the performance of industrialization production and make incentive measures for the PRBs in accord with their industrialization efficiency. The contractors can use this model as a benchmark with others and detect the deficiencies in their industrialization practices. Thus, the proposed model can continuously promote the improvement of the efficiency of industrialization production in the housing industry.

It was also worth noting that this study focused on the industrialization efficiency assessment of buildings at the individual project level, rather than the industry. Thus, macrocriteria, such as supply chain management, and operationrelated criteria were not considered in the assessment process. Another limitation of this study was that the indicators and associated weights were determined by the experts in the Chinese housing industry, which were expected to be affected by the industrialization development in the region.

\section{Conflicts of Interest}

The authors declare that they have no conflicts of interest.

\section{Acknowledgments}

The research was supported by the Scientific Research Experiment Program for the Trunk Steams Embankment Engineering, Heilongjiang Province: research on the operational management system and mechanism for the Sanjiang 
governance engineering (nos. HGZL/KY-17 and HGZL/KY03). The work described in this paper was also funded by the National Key Research \& Development Program (no. 2016YFC0701606).

\section{References}

[1] M. N. A. Azman, M. S. S. Ahamad, T. A. Majid, A. S. Yahaya, and M. H. Hanafi, "Statistical evaluation of pre-selection criteria for industrialized building system (IBS)," Journal of Civil Engineering and Management, vol. 19, no. 1, pp. S131-S140, 2013.

[2] L. Jaillon and C. S. Poon, "The evolution of prefabricated residential building systems in Hong Kong: a review of the public and the private sector," Automation in Construction, vol. 18, no. 3, pp. 239-248, 2009.

[3] M. A. Othuman Mydin, N. M. Sani, and M. Taib, "Industrialised building system in Malaysia: A review," in Proceedings of the Building Surveying and Technology Undergraduate Conference, BUSTUC 2013, mys, June 2013.

[4] X. Zhang, M. Skitmore, and Y. Peng, "Exploring the challenges to industrialized residential building in China," Habitat International, vol. 41, pp. 176-184, 2014.

[5] W. Pan and C. Goodier, "House-building business models and off-site construction take-up," Journal of Architectural Engineering, vol. 18, no. 2, pp. 84-93, 2012.

[6] M. Nasereddin, M. A. Mullens, and D. Cope, "Automated simulator development: A strategy for modeling modular housing production," Automation in Construction, vol. 16, no. 2, pp. 212223, 2007.

[7] N. A. Haron, H. Abdul-Rahman, C. Wang, and L. C. Wood, "Quality function deployment modelling to enhance industrialised building system adoption in housing projects," Total Quality Management and Business Excellence, vol. 26, no. 7-8, pp. 703-718, 2015.

[8] P. Wei, A. G. F. Gibb, and A. R. J. Dainty, "Perspectives of UK housebuilders on the use of offsite modern methods of construction," Construction Management Economics, vol. 25, no. 2, pp. 183-194, 2007.

[9] C. Z. Li, J. Hong, F. Xue, G. Q. Shen, X. Xu, and M. K. Mok, "Schedule risks in prefabrication housing production in Hong Kong: a social network analysis," Journal of Cleaner Production, vol. 134, pp. 482-494, 2016.

[10] X. Cao, X. Li, Y. Zhu, and Z. Zhang, "A comparative study of environmental performance between prefabricated and traditional residential buildings in China," Journal of Cleaner Production, vol. 109, pp. 131-143, 2015.

[11] L. Jaillon, C. S. Poon, and Y. H. Chiang, "Quantifying the waste reduction potential of using prefabrication in building construction in Hong Kong," Waste Management, vol. 29, no. 1, pp. 309-320, 2009.

[12] D. J. De Barba, J. De Oliveira Gomes, and J. F. S. B. De Lacerda, "Sustainability assessment in conventional and industrialized systems built in Brazil," in Proceedings of the 22nd CIRP Conference on Life Cycle Engineering, LCE 2015, pp. 144-149, aus, April 2015.

[13] Y. Chen, G. E. Okudan, and D. R. Riley, "Sustainable performance criteria for construction method selection in concrete buildings," Automation in Construction, vol. 19, no. 2, pp. 235$244,2010$.

[14] M. A. Othuman Mydin, N. M. Sani, and A. F. Phius, "Investigation of industrialised building system performance in comparison to conventional construction method," in Proceedings of the
Building Surveying and Technology Undergraduate Conference, BUSTUC 2013, mys, June 2013.

[15] W. Y. T. Vivian, C. M. Tam, and C. Y. N. William, "On prefabrication implementation for different project types and procurement methods in Hong Kong. Journal of Engineering," Design and Technology, vol. 5, no. 1, pp. 68-80, 2007.

[16] J. H. Meiling, M. Sandberg, and H. Johnsson, "A study of a plan-do-check-act method used in less industrialized activities: Two cases from industrialized housebuilding," Construction Management and Economics, vol. 32, no. 1-2, pp. 109-125, 2014.

[17] V. W. Y. Tam, I. W. H. Fung, M. C. P. Sing, and S. O. Ogunlana, "Best practice of prefabrication implementation in the Hong Kong public and private sectors," Journal of Cleaner Production, vol. 109, pp. 216-231, 2015.

[18] J. Lessing, L. Stehn, and A. Ekholm, "Industrialised housebuilding - Development and conceptual orientation of the field," Construction Innovation, vol. 15, no. 3, pp. 378-399, 2015.

[19] J. Barlow, P. Childerhouse, D. Gann, S. Hong-Minh, M. Naim, and R. Ozaki, "Choice and delivery in housebuilding: Lessons from Japan for UK housebuilders," Building Research and Information, vol. 31, no. 2, pp. 134-145, 2003.

[20] X. Zhang and M. Skitmore, "Industrialized housing in China: a coin with two sides," International Journal of Strategic Property Management, vol. 16, no. 2, pp. 143-157, 2012.

[21] Y.-H. Chiang, E. Hon-Wan Chan, and L. Ka-Leung Lok, "Prefabrication and barriers to entry-a case study of public housing and institutional buildings in Hong Kong," Habitat International, vol. 30, no. 3, pp. 482-499, 2006.

[22] V. W. Y. Tam, C. M. Tam, and W. C. Y. Ng, "On prefabrication implementation for different project types and procurement methods in Hong Kong. Journal of Engineering," Design and Technology, vol. 5, no. 1, pp. 68-80, 2007.

[23] C. Goodier and A. Gibb, "Future opportunities for offsite in the UK," Construction Management and Economics, vol. 25, no. 6, pp. 585-595, 2007.

[24] N. Blismas and R. Wakefield, "Drivers, constraints and the future of offsite manufacture in Australia," Construction Innovation, vol. 9, no. 1, pp. 72-83, 2009.

[25] H. Zabihi, F. Habib, and L. Mirsaeedie, "Definitions, concepts and new directions in Industrialized Building Systems (IBS)," KSCE Journal of Civil Engineering, vol. 17, no. 6, pp. 1199-1205, 2013.

[26] H. M. Alinaitwe, J. Mwakali, and B. Hansson, "Assessing the degree of industrialisation in construction - A case of Uganda," Journal of Civil Engineering and Management, vol. 12, no. 3, pp. 221-229, 2006.

[27] A. M. Kamar, Z. A. Hamid, N. A. Azman, and M. S. S. Ahamad, "Industrialized Building System(IBS): Revisiting Issues of Definition and Classification," International journal of emerging sciences, vol. 1, no. 2, pp. 120-132, 2011.

[28] Y. Chen, G. E. Okudan, and D. R. Riley, "Decision support for construction method selection in concrete buildings: Prefabrication adoption and optimization," Automation in Construction, vol. 19, no. 6, pp. 665-675, 2010.

[29] W. Pan, A. G. Gibb, and A. R. Dainty, "Strategies for Integrating the Use of Off-Site Production Technologies in House Building," Journal of Construction Engineering and Management, vol. 138, no. 11, pp. 1331-1340, 2012.

[30] H. H. Ali and S. F. Al Nsairat, "Developing a green building assessment tool for developing countries - Case of Jordan," Building and Environment, vol. 44, no. 5, pp. 1053-1064, 2009. 
[31] I. Kaya and C. Kahraman, "A comparison of fuzzy multicriteria decision making methods for intelligent building assessment," Journal of Civil Engineering and Management, vol. 20, no. 1, pp. 59-69, 2014.

[32] Mohurd, Standard for assessment of industrialized building, China Architecture and Building Press, Beijing, China, 2015.

[33] A. Gibb, "Standardization and pre-assembly- distinguishing myth from reality using case study research," Construction Management and Economics, vol. 19, no. 3, pp. 307-315, 2001.

[34] H. Jonsson and M. Rudberg, "Classification of production systems for industrialized building: A production strategy perspective," Construction Management and Economics, vol. 32, no. 1-2, pp. 53-69, 2014.

[35] J. Lessing, L. Stehn, and A. Ekholm, "Industrialised housing: Definition and categorization of the concept," in Proceedings of the 13th International Group for Lean Construction Conference, IGLC 13, pp. 471-480, aus, July 2005.

[36] G. Zheng, Y. Jing, H. Huang, and X. Zhang, "Multihierarchical gray evaluation method to assess building energy conservation," Journal of Energy Engineering, vol. 137, no. 2, pp. 88-98, 2011.

[37] E. Šiožinyte and J. Antuchevičiene, "Solving the problems of daylighting and tradition continuity in a reconstructed vernacular building," Journal of Civil Engineering and Management, vol. 19, no. 6, pp. 873-882, 2013.

[38] C. Chang, "Develop a ranking algorithm for the green building project," Quality \& Quantity, vol. 48, no. 2, pp. 911-921, 2014.

[39] L. A. Zadeh, "Fuzzy sets," Information and Control, vol. 8, no. 3, pp. 338-353, 1965.

[40] C.-b. Chen and C. M. Klein, "An efficient approach to solving fuzzy MADM problems," Fuzzy Sets and Systems, vol. 88, no. 1, pp. 51-67, 1997.

[41] W. Pan, A. R. Dainty, and A. G. Gibb, "Establishing and Weighting Decision Criteria for Building System Selection in Housing Construction," Journal of Construction Engineering and Management, vol. 138, no. 11, pp. 1239-1250, 2012.

[42] N. Blismas, C. Pasquire, and A. Gibb, "Benefit evaluation for offsite production in construction," Construction Management and Economics, vol. 24, no. 2, pp. 121-130, 2006.

[43] J. Song, W. R. Fagerlund, C. T. Haas, C. B. Tatum, and J. A. Vanegas, "Considering prework on industrial projects," Journal of Construction Engineering and Management, vol. 131, no. 6, pp. 723-733, 2005.

[44] T. L. Saaty, The analytic hierarchy process: Planning, priority setting, resource Allocation, McGraw-Hill, NY, USA, 1980.

[45] O. Kilincci and S. A. Onal, "Fuzzy AHP approach for supplier selection in a washing machine company," Expert Systems with Applications, vol. 38, no. 8, pp. 9656-9664, 2011.

[46] J. J. Buckley, "Fuzzy hierarchical analysis," Fuzzy Sets and Systems. An International Journal in Information Science and Engineering, vol. 17, no. 3, pp. 233-247, 1985.

[47] T.-Y. Hsieh, S.-T. Lu, and G.-H. Tzeng, "Fuzzy MCDM approach for planning and design tenders selection in public office buildings," International Journal of Project Management, vol. 22, no. 7, pp. 573-584, 2004.

[48] E. Forman and K. Peniwati, "Aggregating individual judgments and priorities with the Analytic Hierarchy Process," European Journal of Operational Research, vol. 108, no. 1, pp. 165-169, 1998.

[49] R. R. Yager, "On a general class of fuzzy connectives," Fuzzy Sets and Systems, vol. 4, no. 3, pp. 235-242, 1980.

[50] C. L. Hwang, M. Beckmann, and H. P. Künzi, Multiple Attribute Decision Making : Methods and Applications A State-of-the-Art Survey, vol. 1, Springer, Berlin, Germany, 1981.
[51] C. Chen, "Extensions of the TOPSIS for group decision-making under fuzzy environment," Fuzzy Sets and Systems, vol. 114, no. 1, pp. 1-9, 2000.

[52] S. J. Chen, M. Beckmann, and W. Krelle, Fuzzy Multiple Attribute Decision Making : Methods and Applications, vol. 1, Springer, Springer, Germany, 1992.

[53] Q. Bao, D. Ruan, Y. Shen, E. Hermans, and D. Janssens, "Improved hierarchical fuzzy TOPSIS for road safety performance evaluation," Knowledge-Based Systems, vol. 32, pp. 84-90, 2012.

[54] X. Sang, X. Liu, and J. Qin, "An analytical solution to fuzzy TOPSIS and its application in personnel selection for knowledgeintensive enterprise," Applied Soft Computing Journal, vol. 30, pp. 190-204, 2015. 


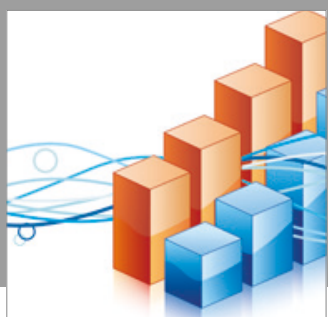

Advances in

Operations Research

vatersals

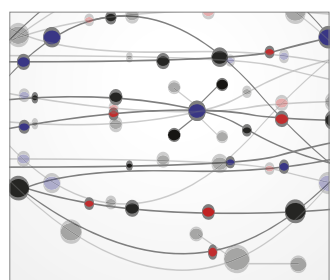

\section{The Scientific} World Journal
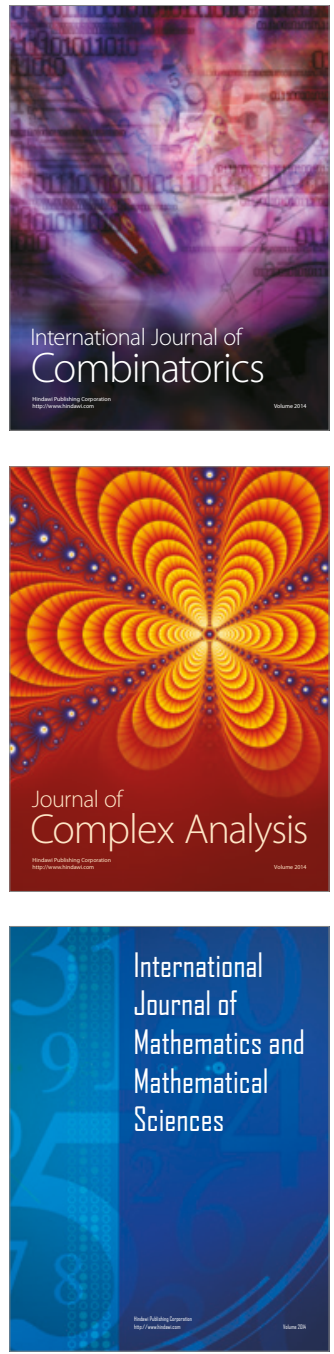
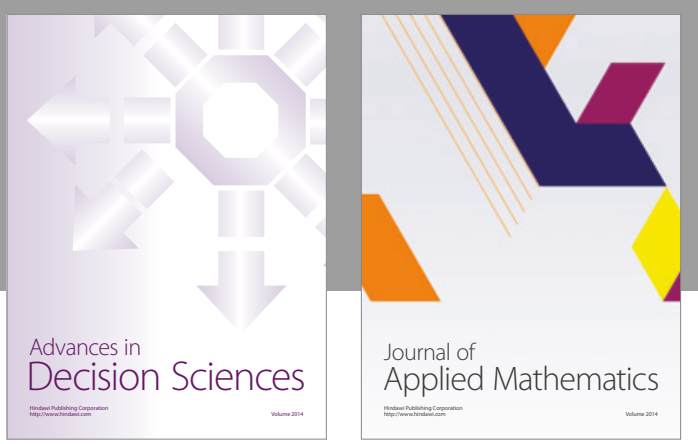

Algebra

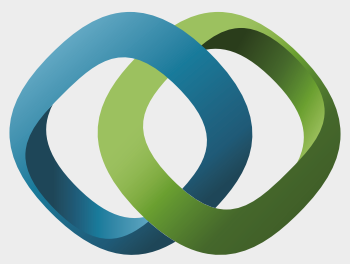

\section{Hindawi}

Submit your manuscripts at

https://www.hindawi.com
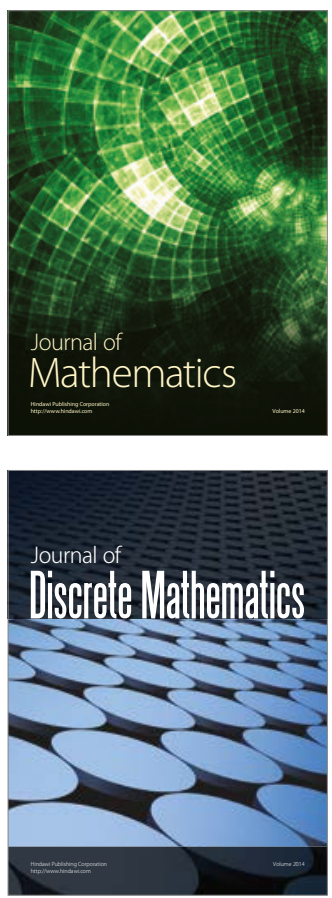

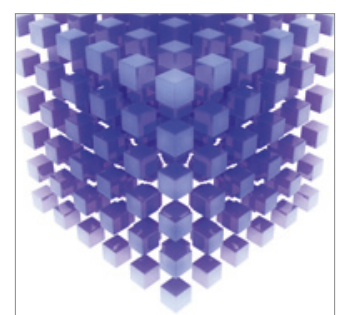

Mathematical Problems in Engineering
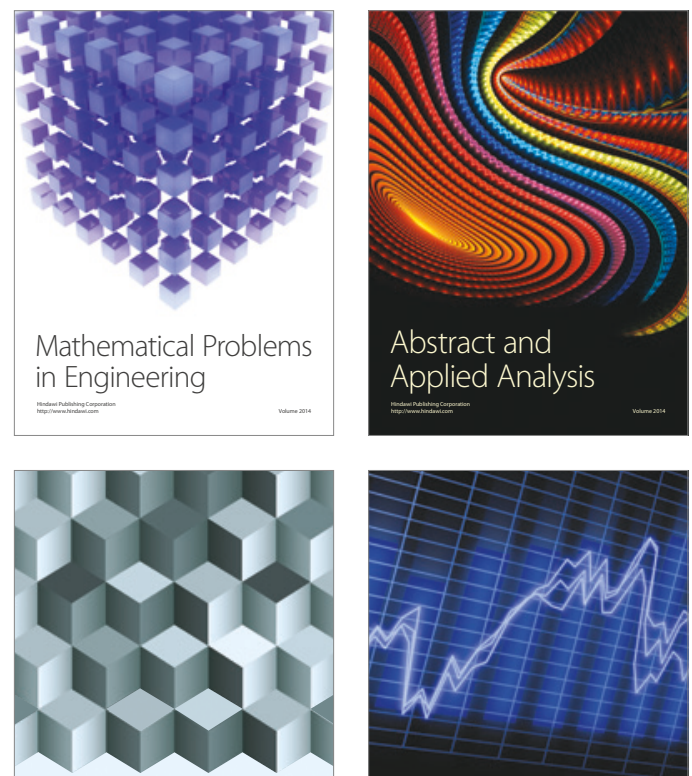

Journal of

Function Spaces

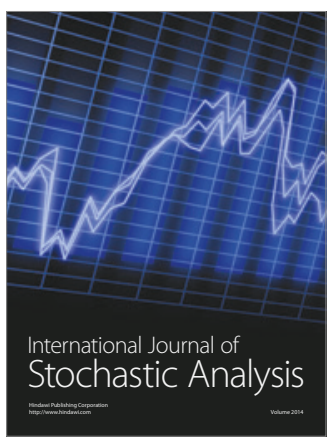

Probability and Statistics
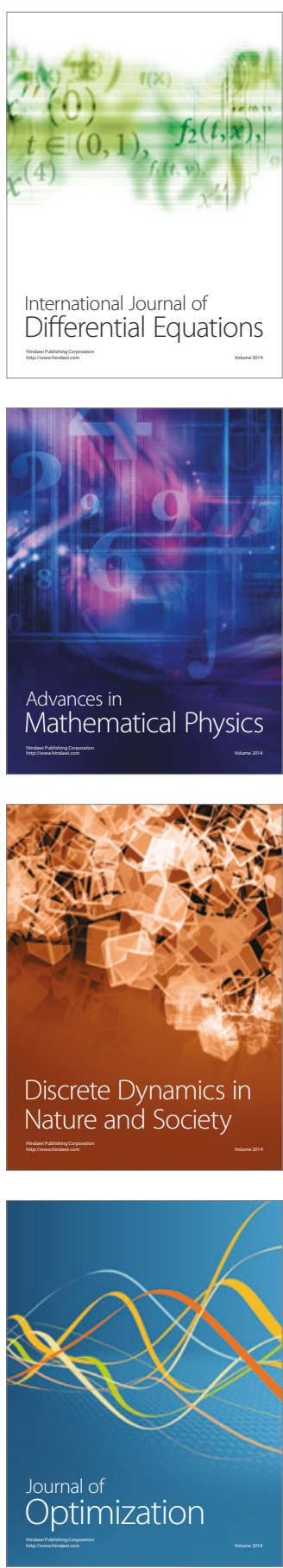